\title{
Penerapan Flexible Space Time Scan Statistics untuk Mengidentifikasi Hotspot Tuberkulosis
}

\author{
Za'ima Nurrusydah \\ Statistisi Pertama, Badan Pusat Statistik Provinsi Sulawesi Tenggara, zaima@bps.go.id \\ Ni Putu Ayu Mila Dewi \\ Statistisi Pertama, Badan Pusat Statistik Provinsi Sulawesi Tenggara,niputu.mila@bps.go.id
}

\begin{abstract}
ABSTRAK, Tuberculosis (TB) merupakan kedaruratan global yang sampai saat ini belum teratasi. Menurut Global Tuberculosis Report 2019, Indonesia menjadi negara dengan kasus TB tertinggi kedua di dunia. Jumlah kasus TB terbanyak di Indonesia berada di Provinsi Jawa Barat. Demi kemajuan program eliminasi TB di Indonesia, maka layanan TB berbasis wilayah sangat diperlukan. Dengan melakukan identifikasi hostpot $\mathrm{TB}$, prioritas untuk menjangkau populasi yang beresiko tinggi dapat dilakukan. Flexible Space Time Scan Statistic (STSS) merupakan salah satu metode analisis spatiotemporal yang mampu mengidentifikasi hotspot TB. Penelitian ini menerapkan Flexible STSS pada kabupaten Bogor yang pada tahun 2018 memiliki jumlah penderita TB terbanyak dibandingkan kabupaten/kota lainnya di Provinsi Jawa Barat. Hasil analisis menunjukkan lima hotspot TB di wilayah kabupaten dan kota Bogor yang sebagian besar tersebar di bagian barat Kabupaten Bogor. Kecamatan Leuwiliang, Leuwisadeng, Cibungbulang, Ciampea, Cigudeg, Nanggung, dan Sukajaya selain memiliki kecenderungan yang tinggi untuk menjadi hotspot TB juga memiliki resiko peningkatan terjadinya TB yang tinggi.
\end{abstract}

Kata Kunci: hotspot, tuberculosis, flexible space time scan statistic, bogor.

\section{PENDAHULUAN}

Sejak tahun 1993, WHO menyatakan bahwa Tuberculosis (TB) merupakan kedaruratan global bagi kemanusiaan. Penderita penyakit menular yang disebabkan oleh Mycobacterium tuberculosis ini selain mengalami penurunan kualitas kesehatan, juga mengalami penurunan kualitas hidup dari sisi ekonomi dan sosial. Akan tetapi, hingga kini belum ada negara yang benar-benar tuntas dari TB.

Pertemuan Ending TB in The Sustainable Development Era di Moskow pada tanggal 16-17 November 2017 menegaskan komitmen dunia untuk mengakhiri TB pada tahun 2030. Tujuan MDGs untuk menurunkan jumlah kasus TB di tahun 2015 telah tercapai, tetapi penurunan kasusnya cenderung sangat lambat, yaitu hanya 2\% tiap tahunnya [1]. Di sisi lain, muncul juga kekhawatiran mengenai resistensi bakteri terhadap antibiotik yang diberikan. Dengan demikian, optimasi riset pendukung sangat diperlukan untuk dapat mengakhiri pandemi TB di tahun 2030.

Menurut Kemenkes RI, tren insiden kasus TB di Indonesia tidak pernah menurun, masih banyak kasus yang belum terjangkau dan terdeteksi [2]. WHO pada Global Tuberculosis Report tahun 2019, memperkirakan jumlah penderita TB di Indonesia pada tahun 2018 mencapai 845 ribu jiwa yang membuat Indonesia menempati posisi tertinggi kedua di dunia dengan jumlah kasus TB setelah India [3]. Jumlah penderita TB yang berhasil terdeteksi pada tahun 2018, berdasarkan data Kemenkes RI, mencapai 511.873 penderita dengan jumlah kasus terbanyak terdapat di Provinsi Jawa Barat [4]. Jumlah penderita TB di Provinsi Jawa Barat sebesar 99.398 jiwa dengan 77,99\% diantaranya berada pada kelompok usia produktif. Pada tahun 2018 Kabupaten Bogor menjadi kabupaten dengan jumlah penderita TB terbanyak di Provinsi Jawa Barat.

Terkait dengan komitmen untuk mewujudkan Indonesia yang bebas dari TB, percepatan dalam kemajuan program eliminasi tuberkulosis di Indonesia sangat diperlukan. Salah satu strategi yang dapat ditempuh adalah memperkuat layanan TB dengan memetakan layanan TB berbasis wilayah. Prioritas harus dilakukan untuk menjangkau populasi yang beresiko tinggi [5]. Hal tersebut sangat penting, mengingat kejadian penyakit merupakan fenomena yang bersandar pada basis wilayah yang mencakup ekosistem dalam dimensi ruang dan waktu, di dalamnya mencakup variabel lingkungan, kependudukan, dan wilayah administratif [6].

Penelitian sebelumnya menekankan pentingnya analisis berbasis spasial dalam penanggulangan TB untuk mendapatkan wilayah 
dengan resiko TB yang tinggi. Supriyanto dan Estri [8] mengevaluasi pola spasial TB di Banyumas menggunakan Fuzzy Set berbasis Sistem Informasi Geografis. Wardani dkk [9] mengelompokkan kejadian TB di Bandar Lampung mengunakan Sistem Informasi Geografis.

Penelitian-penelitian yang telah disebutkan di atas menggunakan analisis spasial untuk mengidentifikasi hotspot TB. Disisi lain, analisis spatiotemporal memiliki kelebihan untuk mempelajari secara bersamaan pola dari waktu ke waktu dan menjelaskan adanya pola yang tidak biasa [10]. Dengan demikian, identifikasi hotspot TB dengan metode spatiotemporal dirasa perlu untuk memberikan insight yang mendalam terhadap kondisi penyebaran TB di Indonesia.

Salah satu metode spatiotemporal untuk mengidentifikasi hotspot adalah Space Time Scan Statistic (STSS). Berdasarkan bentuk jendela pindaiannya STSS dapat dibedakan menjadi Cylindrical STSS, Flexible STSS, dan Square Pyramid Shape STSS.

Menurut Tango dan Takahashi [11], jendela pindaian berbentuk lingkaran (berbentuk silinder pada STSS) sulit untuk mendeteksi secara tepat hotspot yang berbentuk nonlingkaran. Cylindrical STSS cenderung mendeteksi hotspot yang lebih luas dibandingkan hotspot sebenarnya. Sedangkan Flexible STSS mampu untuk mendeteksi hotspot dengan lebih baik karena bentuk jendela pindaiannya yang fleksibel dapat mengikuti bentuk geografis dari wilayah penelitian. Oleh karena itu, penelitian ini akan mengidentifikasi hotspot TB di Kabupaten Bogor dan Kota Bogor menggunakan Flexible STSS.

\section{TINJAUAN PUSTAKA}

\section{Hotspot}

Hotspot merupakan lokasi atau wilayah yang secara konsisten memiliki tingkat kejadian yang tinggi dan mungkin memiliki karakteristik yang berbeda dengan daerah di sekitarnya [7].

\section{Flexible Space Time Scan Statistic}

Flexible Space Time Scan Statistics (Flexible STSS) adalah metode scan statistic tiga dimensi dengan menggunakan jendela pindaian berbentuk fleksible. Metode ini pertama kali dikembangkan oleh Tango dan Takahashi [12]. Flexible STSS memiliki tiga tahapan utama yaitu pembentukan zona, penghitungan statistik uji, dan pengujian hipotesis.

\section{Pembentukan zona}

Pembentukan zona pada Flexible STSS diawali dengan mencari centroid atau titik tengah dari masing-masing kecamatan. Selanjutnya centroid digunakan untuk menentukan matriks kedekatan. Kemudian dibuat himpunan basis jendela pindaian. Pada Flexible STSS jendela pindaian berbentuk perismatik dengan basis berbentuk fleksible yang terdiri dari $\mathrm{k}$ daerah terhubung $(1 \leq k \leq K)$. Sedangkan tingginya merupakan dimensi waktu.

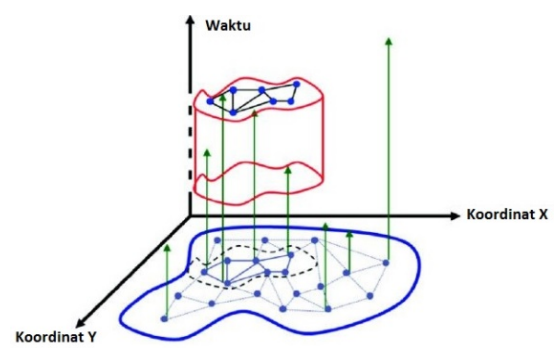

Gambar 1. Ilustrasi jendela pindaian pada Flexible STSS

$Z_{i k(j)}$ pada Flexible STSS menotasikan basis ke $j$ dari jendela prismatik yang merupakan sekumpulan wilayah $k$ yang terhubung mulai dari wilayah $i$, dan $j_{i k}$ adalah jumlah $j$ yang memenuhi $Z_{i k(j)} \subseteq Z_{i k}$ untuk $k=1, \ldots, K$.

$$
Z=\left\{Z_{i k(j)} \mid i=1, \ldots, m_{S}\right\}
$$

dimana :

$$
k=1, \ldots, K, j=1, \ldots, j_{i k}
$$

Misalkan $Y$ adalah himpunan ketinggian dengan interval $m_{T}$ dari titik waktu diskrit termasuk waktu saat ini yaitu $t_{p}$.

$Y=\left\{I_{1}, \ldots, m_{T}\right\}$ dimana

$I_{u}=\left\{t_{p}-u+1, t_{p}\right\}$ dimana $\left(u=1, \ldots, m_{T}\right)$

Daerah pindaian dibatasi ke dalam himpunan $W=Z x Y$

\section{Penghitungan statistik uji}

Statistik uji yang digunakan dalam metode scan statistic adalah maksimum likelihood ratio dari seluruh kemungkinan zona. Nilai statistik uji 
dihitung untuk seluruh kemungkinan zona yang terbentuk.

Space time scan statistic mengasumsikan sebaran peluang Poisson untuk jumlah kejadian TB di suatu wilayah. Sehingga nilai maksimum likelihood ratio dari seluruh kemungkinan zona dapat dihitung menggunakan formula sebagai berikut :

$\lambda=\sup _{Z \in Z} \frac{\left(\frac{n_{Z}}{\mu(Z)}\right)^{n_{Z}}\left(\frac{n_{G}-n_{Z}}{\mu(G)-\mu^{\prime}(Z)}\right)^{n_{G}-n_{Z}}}{\left(\frac{n_{G}}{\mu(G)}\right)^{n_{G}}} I\left(\frac{n_{Z}}{\mu(Z)}>\frac{n_{G}-n_{Z}}{\mu(G)-\mu(Z)}\right)$

dimana :

$\lambda \quad: \quad$ Likelihood ratio

$\mu(Z) \quad$ : Nilai harapan di dalam zona

$\mu(G) \quad$ : Nilai harapan di wilayah penelitian

$n_{G} \quad: \quad$ Jumlah kasus di wilayah penelitian

$n_{Z} \quad: \quad$ Jumlah kasus di dalam zona

Nilai likelihood ratio (LLR) ini dapat memberikan gambaran kecenderungan suatu wilayah untuk menjadi hotspot TB. Semakin tinggi nilai LLR maka semakin mungkin suatu wilayah menjadi hotspot TB. Resiko relatif (RR) dalam scan statistic merupakan resiko relatif dari wilayah yang ada dalam zona yang mempunyai resiko untuk terjadinya kasus tertentu sebesar RR kali dibandingkan wilayah di luar zona [12]. Nilai RR lebih dari 1 menunjukkan peningkatan resiko. Artinya wilayah tersebut memiliki resiko tinggi untuk terjadinya kasus dan menjadi kandidat hotspot.

$$
R R=\frac{n_{Z}}{\mu(Z)}
$$

\section{Pengujian hipotesis}

Simulasi Monte Carlo digunakan untuk pengujian hipotesis pada metode scan statistic. Langkah-langkah pengujian hipotesis menggunakan Simulasi Monte Carlo adalah sebagai berikut :

1. Menghitung nilai statistik uji (likelihood ratio) dari data asli
2. Berdasarkan hipotesis nol maka dibangkitkan sejumlah besar contoh acak.

3. Menghitung nilai likelihood ratio pada contoh acak yang telah dibangkitkan pada langkah kedua.

4. Mengurutkan nilai likelihood ratio dari data asli maupun himpunan data acak. Jika peringkat statistik uji pada data asli (R) berada pada $\alpha$ persen tertinggi dari statistik uji himpunan data acak, maka tolak $\mathrm{H} 0$ pada level signifikansi sebesar $\alpha$ persen.

$$
P-\text { value }=\frac{R}{1+m}
$$

$\mathrm{m}$ adalah banyak contoh acak yang dibangkitkan

\section{METODOLOGI}

\section{Sumber data}

Data yang digunakan pada penelitian ini merupakan data sekunder yang diperoleh dari Badan Pusat Statistik (BPS) Kabupaten Bogor dan Kota Bogor tahun 2014-2018. Satuan pengamatan adalah seluruh kecamatan pada Kabupaten Bogor dan Kota Bogor, hal ini mengingat Kota Bogor berada di tengah wilayah Kabupaten Bogor. Peubah yang digunakan dalam penelitian adalah jumlah penduduk dan jumlah kasus TB terdeteksi tahun 2014-2018.

\section{Prosedur Analisis}

Langkah-langkah yang dilakukan pada penelitian ini meliputi

1. Eksplorasi data TB

2. Analisis hotspot dengan Flexible Space Time Scan Statistics

\section{PEMBAHASAN}

\section{Hotspot TB}

Pada penelitian ini, jumlah kecamatan yang dapat masuk ke dalam hotspot dibatasi paling banyak lima kecamatan. Gambar 2 menunjukkan lima hotspot TB dengan urutan prioritasnya. Seluruh hotspot yang terbentuk menunjukkan tempat terjadinya peningkatan resiko terjadinya TB. Hampir seluruh kecamatan yang menjadi hotspot TB berada di wilayah Kabupaten Bogor, sedangkan di wilayah Kota Bogor hanya 
Kecamatan Bogor Selatan yang menjadi hotspot TB.

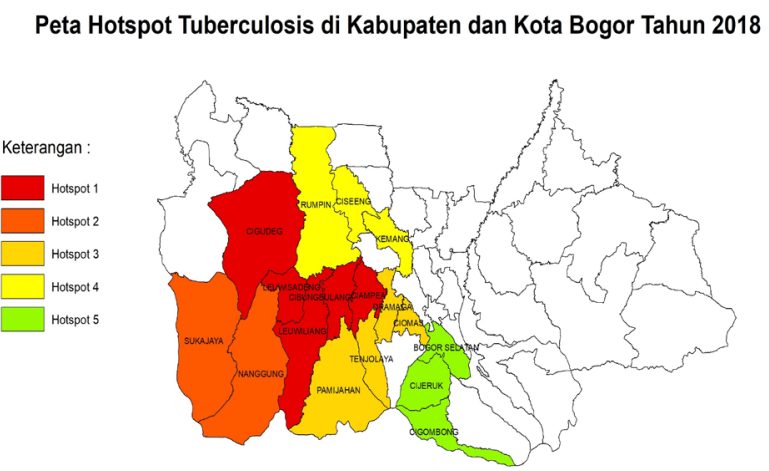

Gambar 2. Peta Hotspot TB di Kabupaten dan Kota Bogor Tahun 2018

Tabel 1. Hotspot TB menurut LLR dan RR di Kabupaten dan Kota Bogor

\begin{tabular}{clcc}
\hline $\begin{array}{c}\text { Hot } \\
\text {-spot }\end{array}$ & \multicolumn{1}{c}{ Kecamatan } & LLR & RR \\
\hline 1 & $\begin{array}{l}\text { Leuwiliang, } \\
\text { Leuwisadeng, } \\
\text { Cibungbulang, } \\
\text { Ciampea, Cigudeg }\end{array}$ & 311,77 & 1,52 \\
\hline 2 & $\begin{array}{l}\text { Nanggung, } \\
\text { Sukajaya }\end{array}$ & 242,016 & 2,24 \\
\hline 3 & $\begin{array}{l}\text { Pamijahan, } \\
\text { Tenjolaya, } \\
\text { Dramaga, Ciomas }\end{array}$ & 70,11 & 1,59 \\
\hline 4 & $\begin{array}{l}\text { Kemang, Ciseeng, } \\
\text { Rumpin }\end{array}$ & 60,42 & 1,64 \\
\hline 5 & $\begin{array}{l}\text { Cijeruk, } \\
\text { Cigombong, Bogor } \\
\text { Selatan }\end{array}$ & & \\
\hline
\end{tabular}

Urutan hotspot pada Tabel 1 menunjukkan urutan prioritas. Hotspot 1 merupakan hotspot dengan prioritas pertama, hotspot 2 merupakan hotspot dengan prioritas kedua, dan seterusnya dimana hotspot 5 merupakan hotspot dengan prioritas kelima. Hotspot dengan prioritas tertinggi pertama berada di wilayah kecamatan
Cigudeg, Leuwisadeng, Cibungbulang, Leuwiliang, dan Ciampea. Keseluruhan wilayah ini berada di Kabupaten Bogor. Kecamatan Cigudeg, Cibungbulang, Ciampea, dan Leuwiliang memiliki jumlah penderita TB yang sangat tinggi dan cenderung meningkat tajam dari tahun ke tahun. Sementara itu, Kecamatan Leuwisadeng meskipun memiliki jumlah penderita TB yang lebih sedikit namun letaknya berada diantara hotspot 2 dan 4. Hal ini dapat mengindikasikan bahwa Kecamatan Leuwisadeng memerlukan perhatian yang lebih agar tidak terjadi peningkatan prevalensi TB karena pengaruh dari wilayah di sekitarnya.

Hotspot dengan prioritas tertinggi kedua berada di wilayah kecamatan Sukajaya dan Nanggung. Kedua kecamatan tersebut mengalami peningkatan jumlah penderita TB yang sangat tajam, terutama Kecamatan Nanggung yang mengalami peningkatan sebesar $155,06 \%$. RR dari hotspot 2 juga menjadi yang tertinggi dibandingkan dengan hotspot lainnya, artinya kecamatan pada hotspot 2 memiliki resiko untuk terjadinya kasus TB 2,24 kali dibandingkan kecamatan di luar hotspot 2 .

Hotspot dengan prioritas tertinggi ketiga berada di wilayah kecamatan Dramaga, Ciomas, Tenjolaya, dan Pamijahan. Seluruh kecamatan dalam hotspot ini memiliki jumlah penderita TB yang tinggi dan cenderung terus meningkat kecuali Kecamatan Tenjolaya. Letak Kecamatan Tenjolaya yang berada di tengah-tengah hotspot ke 4 dapat mengindikasikan bahwa kecamatan ini memerlukan tindakan pencegahan agar tidak terjadi peningkatan kasus TB.

Hotspot keempat berada di wilayah Kecamatan Rumpin, Ciseeng, dan Kemang. Seluruh kecamatan ini mengalami peningkatan jumlah penderita TB setiap tahunnya terutama pada tahun 2018.

Hotspot kelima berada di wilayah kecamatan Bogor Selatan, Cijeruk, dan Cigombong. Seluruh kecamatan di dalam hotspot ini memiliki jumlah penderita TB yang cukup tinggi terutama Kecamatan Bogor Selatan.

\section{KESIMPULAN}

Secara umum, hotspot TB banyak teridentifikasi di Kabupaten Bogor bagian barat. Hotspot 1 dan 2 memerlukan perhatian yang lebih 
dibandingkan hotspot lainnya karena selain memiliki kecenderungan yang tinggi untuk menjadi hotspot juga memiliki peningkatan resiko terjadinya TB yang tinggi.

\section{DAFTAR PUSTAKA}

[1] WHO. 2018. "Research for Tuberculosis Elimination". [Internet]. [diakses 18 Februari 2020]. Tersedia pada https://www.who.int/tb/publications/TB_r esearch.pdf?ua $=1$.

[2] Kementrian Kesehatan Republik Indonesia. 2018. " Kemenkes Percepat Atasi 3 Masalah Kesehatan”. [Internet]. [diakses 18 Februari 2020]. Tersedia pada http://sehatnegeriku.kemkes.go.id/baca/rili s-media/20180305/2425127/rakerkesnas2018-kemenkes-percepat-atasi-3-masalahkesehatan/.

[3] WHO. 2019. "Global Tuberculosis Report 2019". Geneva: WHO.

[4] Kementrian Kesehatan Republik Indonesia. 2019. "Data dan Informasi Profil Kesehatan Indonesia 2018”. Jakarta: Kementrian Kesehatan Republik Indonesia.

[5] Riono. Pandu. 2018. "Eliminasi Tuberkulosis di Indonesia : Tantangan dan Peluang”. [Internet]. [diakses 18 Februari 2020]. Tersedia pada https://www.kemkes.go.id/resources/down load/infoterkini/materi\%20pra\%20rakerke snas\%202018/Pakar\%20TBC.pdf

[6] Achmadi, UF. 2009. "Manajemen Penyakit Berbasis Wilayah", Jurnal Kesehatan Masyarakat Nasional, vol.3, no. 4, pp. 147-153

[7] Haran M, Molinero J, Patil GP. 2006. "Large Scale Plant Disease Forecasting: Case Study of Fusarium Head Blight". Center for Statistical Ecology and Environmental Statistics. DGO 2006 Conference

[8] Estri MN, Supriyanto. 2009. "Evaluasi Pola Spasial Tuberkulosis di Banyumas Menggunakan Fuzzy Set Berbasis Sistem Informasi Geografis", Jurnal Ilmiah Matematika \& Pendidikan Matematika, vol. 1 , no. 1 , pp. 7-17.
[9] Wardani DW, Lazuardi L, Mahendradhata Y, Kusnanto, H. 2014. "Clustered Tuberculosis Incidence in Bandar Lampung, Indonesia", WHO South-East Asia Journal of Public Health, vol. 3, no. 2, pp. 179-185.

[10] Columbia University. 2018. Spatiotemporal Analysis [Internet]. [diakses Desember 2018]. Tersedia pada https://www.publichealth.columbia.edu/re search/population-healthmethods/spatiotemporal-analysis

[11] Tango T, Takahashi K. 2005. “A Flexibly Shaped Spatial Scan Statistic for Detecting Clusters". International Journal of Helath Geographics. 4(1):11-25.

[12] Haining RP. 2003. "Spatial Data Analysis: Theory and Practice”. Cambridge (UK): Cambridge University Press. 